\title{
Electrodeposition of Polypyrrole Films on Aluminum Surfaces from a p-toluene Sulfonic Acid Medium
}

\author{
Andréa Santos Liu, Marcia Cristina Bezerra, Liu Yao Cho* \\ Organic Electrochemistry Laboratory, Institute for Research and Development -IP\&D, \\ Universidade do Vale do Paraiba - UNIVAP, \\ Av. Shishima Hifumi, 2911, 12244-000 São José dos Campos - SP, Brazil
}

Received: August 13, 2009; Revised: November 22, 2009

\begin{abstract}
Electrodeposition of polypyrrole films on aluminum from aqueous solutions containing p-toluene sulfonic acid and pyrrole was performed by cyclic voltammetry and galvanostatic technique. The influence of applied current density on the morphology of the films was studied by Scanning Electron Microscopy. The films displayed a cauliflower-like structure consisting of micro-spherical grains. This structure is related to dopand intercalation in the polymeric chain. Films deposited at higher current density were more susceptible to the formation of pores and defects along the polymeric chain than films deposited at lower current density. These pores allow the penetration of aggressive species, thereby favoring the corrosion process.
\end{abstract}

Keywords: electrodeposition, polypyrrole, aluminum, p-toluene sulfonic acid

\section{Introduction}

Currently chromates are used to protect aluminum surfaces against corrosion. However, these inhibitors have high toxicity and environment problems ${ }^{1,2}$. Conducting polymers represent a class of materials that might replace chromate conversion coating in aluminum corrosion control ${ }^{3-5}$.

Barrier, inhibitor, anodic protection, and the mediation of oxygen reduction have been suggested to explain the aluminum corrosion protection of conducting polymer ${ }^{6}$.

Proposed mechanism to explain the anticorrosion activity of conducting polymer is:

1) The reaction of metal $(\mathrm{M})$ oxidation and conducting polymer $(\mathrm{CP})$ reduction, which results in the growth of a passive oxide $\mathrm{M}(\mathrm{OH})$ layer.

$\mathrm{M}+\mathrm{CP}^{+\mathrm{m}}+\mathrm{y} \mathrm{H}_{2} \mathrm{O} \rightarrow \mathrm{M}(\mathrm{OH})_{\mathrm{y}}+\mathrm{CP}^{0}+\mathrm{y} \mathrm{H}^{+}$

2) The reaction of polymer oxidation and oxygen reduction.

$\mathrm{O}_{2}+2 \mathrm{H}_{2} \mathrm{O}+\mathrm{CP}^{0} \rightarrow \mathrm{CP}^{+\mathrm{m}}+4 \mathrm{OH}^{-}$

Polypyrrole (PPy) is a conducting polymer that has been extensively investigated because of its high conductivity and environmental stability as well as its possible use in a wide range of applications such as membranes, sensors, batteries, and anti-corrosion films ${ }^{7,8}$.

PPy films can be synthesized from aqueous or organic media by chemical and electrochemical methods. Electrochemical synthesis is more advantageous since the coating properties can be controlled by varying parameters such as current density, monomer concentration, electrolyte solution, and $\mathrm{pH}^{9}$.

Various research groups have reported the electrodeposition of PPy on aluminum surfaces in different electrolytes, such as sulfuric acid, sulfonates, sulfosuccinate, and oxalic acid ${ }^{10-14}$. The type of pre-treatment (polishing or galvanostatic activation), electrolyte, and solvent (aqueous or organic) affect the electropolymerization process on aluminum surfaces.

Our previous works have shown the electrodeposition of adherent and homogeneous PPy films on aluminum surfaces from aqueous solutions containing carboxylic acids. Doped films can be deposited depending on the synthesis conditions, such as electrolyte, $\mathrm{pH}$, and deposition potential ${ }^{15,16}$. The electrolyte plays an important role in determining the porosity of the oxide film formed under the PPy film. Additionally, the electrolyte can participate as dopant and incorporate onto PPy film ${ }^{16}$.

Studies have also shown that the corrosion protection of aluminum surfaces by PPy films depends on synthesis conditions. Saidman et al. reported that localized corrosion occurred when the polymercoated electrode was exposed to chloride ions, when the polymer was electrodeposited on aluminum from nitric acid ${ }^{17}$. Ocon et al. showed a good performance corrosion of the PPy films electrodeposited in oxalic acid on aluminum surfaces ${ }^{18}$. Additionally, Paloumpa et al. studied the corrosion protection of aluminum surfaces by PPy chemically deposited from phosphoric acid and conclude that coated surfaces presented excellent corrosion resistance ${ }^{19}$.

Aromatic sulfonates can act as dopants to PPy and influence the electrical and electrochemical properties of PPy films ${ }^{20,21}$.

Although the corrosion performance of PPy films deposited in sulfonic acid media have been reported for iron surfaces ${ }^{22}$, the corrosion protection of aluminum surfaces coated with PPy films deposited from a p-toluene sulfonic acid medium has not been investigated.

This work presents results of the electrodeposition of PPy films on aluminum surfaces in aqueous solutions containing p-toluene sulfonic acid and the behavior of the films with respect to corrosion prevention of the aluminum surfaces.

\section{Experimental}

Electrochemical experiments were carried out using a Potentiostat/Galvanostat (Model MQPG-01 Microquimica) and were performed at $25{ }^{\circ} \mathrm{C}$ in a one-compartment cell containing three electrodes. The working electrodes were $99.9 \% \mathrm{w}$ aluminum inlaid on Teflon ${ }^{\circledR}$, with a $0.53 \mathrm{~cm}^{2}$ disc shaped exposed area. The reference electrode was a saturated $\mathrm{Ag} / \mathrm{AgCl}, \mathrm{Cl}^{-}$electrode, and the auxiliary electrode was a platinum wire.

The aluminum surfaces were polished with abrasive paper (220, 400, 600 and 1200 grits) and rinsed with distilled water before each electrochemical experiment. 
PPy electrodeposition was carried out by cyclic voltammetry by scanning the potential between -1.0 and $2.0 \mathrm{~V}$ vs. $\mathrm{Ag} / \mathrm{AgCl}$ at a sweep rate of $5.0 \mathrm{mV} / \mathrm{s}$. The PPy film growth was also performed using the galvanostatic technique, by applying current densities ranging between 1.0 and $10.0 \mathrm{~mA} . \mathrm{cm}^{-2}$ to the working electrode.

The electrolytic solution was prepared by dissolving $0.2 \mathrm{~mol} . \mathrm{L}^{-1}$ p-toluene sulfonic acid $+0.5 \mathrm{~mol} . \mathrm{L}^{-1}$ pyrrole in distilled water.

The morphology of surfaces coated with the polypyrrole films was analyzed using a Jeol ${ }^{\circledR}$ JXA-840A Scanning Electron Microscope (SEM). The micrographs were obtained using a $15 \mathrm{keV}$ electron beam.

Fourier transform infrared spectroscopy (FTIR) was used to analyze the compositions of the PPy films. The spectra were obtained with a spectrometer model SPECTRUM-2000 (Perkin Elmer). The analysis conditions were: wavenumber range of $4000-400 \mathrm{~cm}^{-1}, 4 \mathrm{~cm}^{-1}$ resolution, 40 scans, and room temperature $\left(25^{\circ} \mathrm{C}\right)$. $\mathrm{KBr}$ pellets were prepared with solid p-toluene sulfonic acid and with the PPy films removed from the aluminum surfaces. The analysis of the liquid pyrrole was performed using the capillary liquid film technique.

The corrosion protection of aluminum surfaces by PPy films was investigated by potentiodynamic polarization curves in a $0.1 \mathrm{~mol} . \mathrm{L}^{-1}$ $\mathrm{NaCl}$ solution $(\mathrm{pH}=5.9)$, which was not stirred, open to the atmosphere, and at a temperature of $25^{\circ} \mathrm{C}$. The experiments were carried out by varying the electrode's potential, at $5 \mathrm{mV} / \mathrm{s}$, from $-1.0 \mathrm{~V}$ up to $+1.5 \mathrm{~V}$ and reversing the potential down to $-1.0 \mathrm{~V}$. The corrosion potential and the corrosion current density were obtained from the Tafel plots.

\section{Results and Discussion}

\subsection{Electrodeposition of polypyrrole}

Our previous work reported on the electrodeposition of homogeneous and adherent PPy films using 0.2 mol. $\mathrm{L}^{-1}$ electrolyte (organic acids) and 0.5 mol. $\mathrm{L}^{-1}$ monomer. In $0.2 \mathrm{~mol} . \mathrm{L}^{-1}$ electrolyte, a porous aluminum oxide layer was formed, favoring the PPy film growth. Furthermore, the higher the monomer concentration was, the faster the oxidation reaction of pyrrole at the aluminum/electrolyte solution interface, and the electropolymerization process commenced at lower oxidation potential ${ }^{15,16}$. Higher electrodeposition potential was undesirable since overoxidized PPy films were formed.

Figure 1 shows the first cycle for the cyclic voltammetry performed to investigate the electrodeposition of PPy from 0.2 mol.L $\mathrm{L}^{-1}$

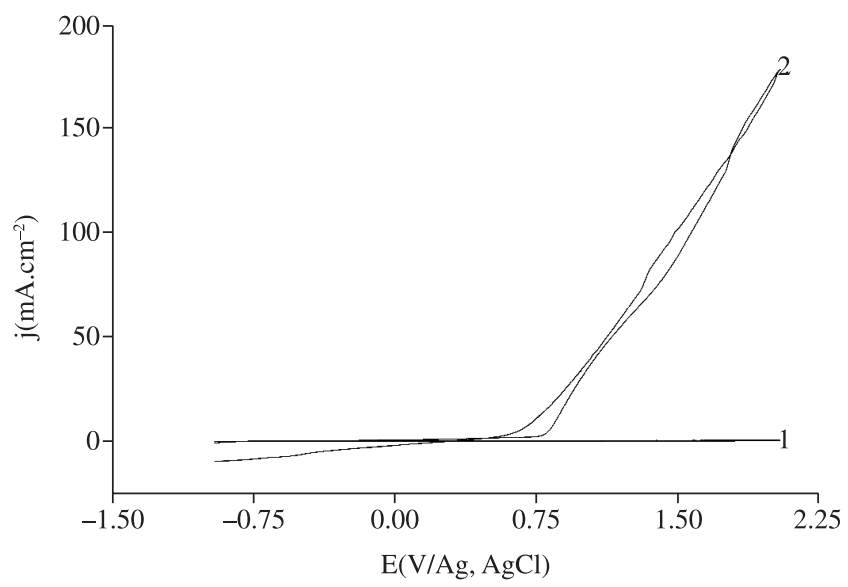

Figure 1. Cyclic voltammograms of $\mathrm{Al}$ polarized in aqueous solutions of: (1) 0.2 mol. $\mathrm{L}^{-1}$ p-toluene sulfonic acid and (2) $0.2 \mathrm{~mol} . \mathrm{L}^{-1} \mathrm{p}$-toluene sulfonic acid and $0.5 \mathrm{~mol} . \mathrm{L}^{-1}$ pyrrole. Scan rate: $5 \mathrm{mV} / \mathrm{s}$. p-toluene sulfonic acid solutions ( $\mathrm{pH} 1.5)$ and 0.8 mol.L $\mathrm{L}^{-1}$. The cyclic voltammogram for the aluminum electrode in monomer free 0.2 mol. $\mathrm{L}^{-1} \mathrm{p}$-toluene sulfonic acid aqueous solution showed that the surface was passive. Curve 2 in Figure 1 illustrates that the anodic currents increase at about $0.75 \mathrm{~V}$ which indicates pyrrole oxidation.

The polymerization process was also performed using the galvanostatic technique. Figure 2 shows the potential-time curves obtained for PPy deposition from aqueous solutions containing p-toluene sulfonic acid $\left(0.2 \mathrm{~mol} . \mathrm{L}^{-1}\right)$ and pyrrole $\left(0.5 \mathrm{~mol} . \mathrm{L}^{-1}\right)$ while varying the current density between 0.5 and $10.0 \mathrm{~mA} \cdot \mathrm{cm}^{-2}$.

Increases in current density (a) shifted the working potential to values that are more positive and (b) increased PPy film thickness. At lower current densities ( 0.5 and $\left.2.5 \mathrm{~mA} \mathrm{~cm}^{-2}\right)$, homogeneous PPy films on aluminum surfaces did not form. However, at $5.0 \mathrm{~mA} . \mathrm{cm}^{-2}$, the PPy film was homogeneous and the potential stabilizes at $0.79 \mathrm{~V}$ vs. $\mathrm{Ag} / \mathrm{AgCl}$ and remained constant even about $2 \mathrm{~h}$ after switching on the current. This result is in accordance with that observed in cyclic voltammetry, in which the PPy growth commenced at $0.75 \mathrm{~V}$ vs. $\mathrm{Ag} / \mathrm{AgCl}$ (curve 2 in Figure 1).

Moreover, the potential oscillated when $10.0 \mathrm{~mA} \cdot \mathrm{cm}^{-2}$ was applied. This result was associated with side reactions (overoxidation) that occur in the polymer matrix at higher potentials. The reactions that occured during the overoxidation process are represented below $^{23,24}$ (Figure 3).

Previous results have shown that the formation of overoxidized films onto aluminum surfaces depend on the electrolyte $\left(\mathrm{A}^{-}\right)$nature. ${ }^{16}$ In citric acid medium the plateau potential for galvanostic deposition was $1.5 \mathrm{~V}$ vs $\mathrm{Ag} / \mathrm{AgCl}$ resulting in the overoxidized film that was confirmed by the presence of carbonyl in the FTIR spectrum.

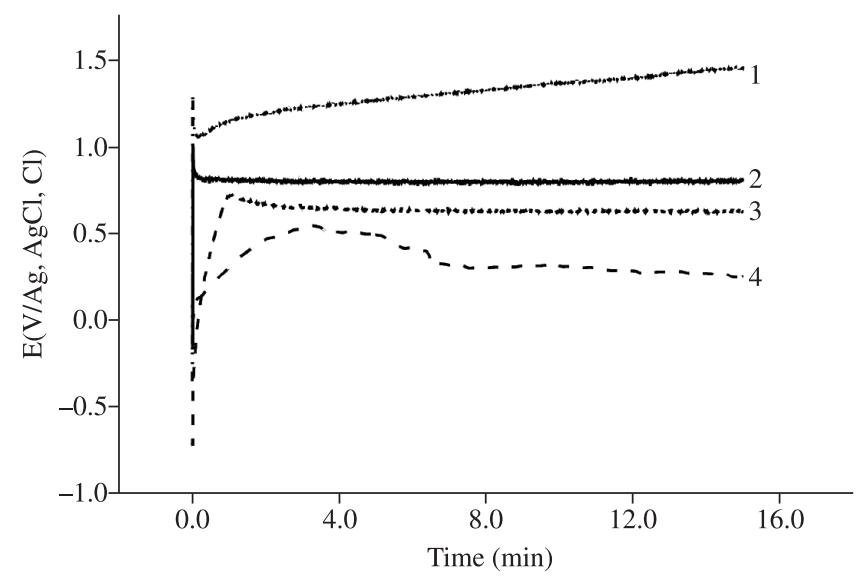

Figure 2. Potential-time curves for PPy electrodeposition from 0.2 mol. $\mathrm{L}^{-1}$ p-toluene sulfonic acid $+0.5 \mathrm{~mol} . \mathrm{L}^{-1}$ pyrrole. The applied current densities (mA cm-2) were: 1) 10.0 ;2) 5.0 ; 3) 2.5 and 4) $0.5 \mathrm{~mA} . \mathrm{cm}^{-2}$.

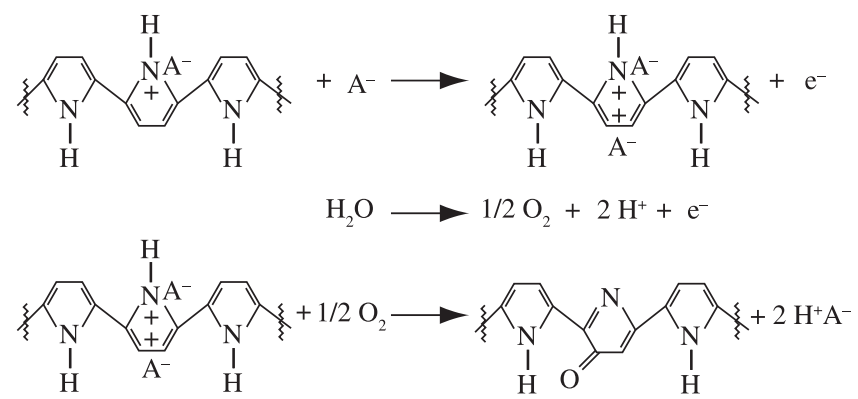

Figure 3. The overoxidation process in the polymer matrix at higher potentials. 
Bazzaoui et al. reported that the PPy eletrodeposited is overoxidized in saccharin aqueous medium at potential higher than $1 \mathrm{~V}$ vs. $\mathrm{Ag} / \mathrm{AgCl}^{25}$.

\subsection{Characterization of PPy films}

The composition of PPy films electrodeposited in p-toluene sulfonic acid was analyzed by FTIR (Figure 4).

The presence of the absorption bands at: $1635 \mathrm{~cm}^{-1}$ (axial def. $\mathrm{C}=\mathrm{C}$ ); $1302 \mathrm{~cm}^{-1}$ (asymmetric axial def. $\mathrm{O}=\mathrm{S}=\mathrm{O}$ ); and $1132 \mathrm{~cm}^{-1}$ (symmetric axial def. $\mathrm{O}=\mathrm{S}=\mathrm{O}$ ) assigned in the spectrum of the PPy film (Figure 4a) suggested that the p-toluene sulfonic acid was incorporated into the polymer as a dopant.

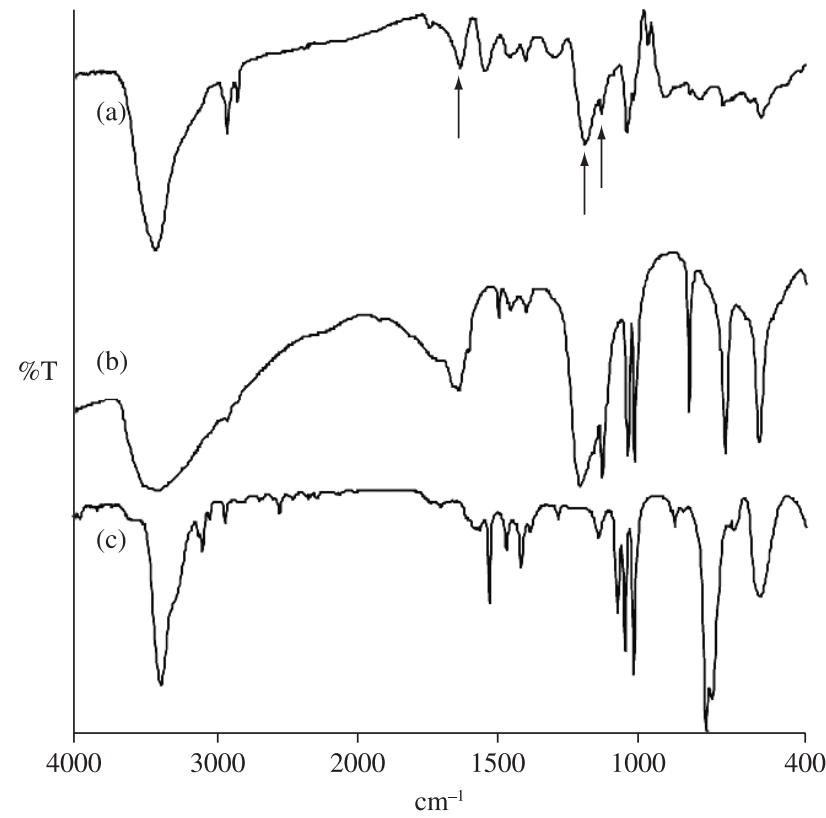

Figure 4. FTIR spectra of: a) PPy films deposited on aluminum at $5.0 \mathrm{~mA} . \mathrm{cm}^{-2}$; b) p-toluene sulfonic acid and c) pyrrole.

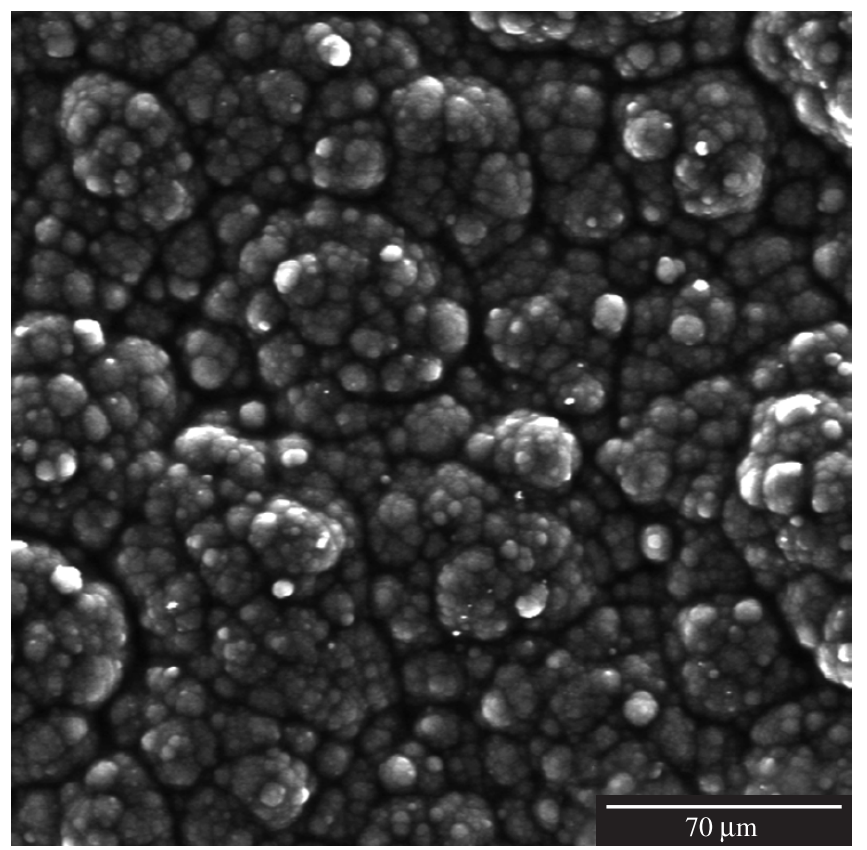

(a)
Figure 5 shows the SEM micrographs of the aluminum surfaces coated with PPy films electrodeposited at 5.0 and $10.0 \mathrm{~mA} . \mathrm{cm}^{-2}$ and at the same deposition charge of $9.0 \times 10^{4} \mathrm{C} . \mathrm{m}^{-2}$.

The films displayed a cauliflower-like structure of micro-spherical grains. This cauliflower structure is related to the dopant intercalation difficulty in the disordered polymeric chain ${ }^{26}$.

The micrographs also showed that the PPy films deposited at $10.0 \mathrm{~mA} . \mathrm{cm}^{-2}$ had larger voids between the grains and were less homogeneous than those formed at $5.0 \mathrm{~mA} . \mathrm{cm}^{-2}$. The morphological differences between the films can be explained by the overoxidation which results in the formation of pores and defects along the PPy chain.

\subsection{Corrosion tests}

The corrosion resistance of aluminum surfaces coated with PPy films was investigated in chloride containing medium.

Figure 6 shows potentiodynamic polarization curves at $5 \mathrm{mV} / \mathrm{s}$, in a 0.1 mol. $\mathrm{L}^{-1} \mathrm{NaCl}$ aqueous solution (not stirred, $\mathrm{pH}$ 5.9) for uncoated aluminum surfaces and for surfaces coated with PPy films electrodeposited at 5.0 and $10.0 \mathrm{~mA} . \mathrm{cm}^{-2}$ and at the same deposition charge of $9.0 \times 10^{4}$ C. $\mathrm{m}^{-2}$.

The corrosion potential of the aluminum surfaces coated with polymeric films shifted to less negative values, and the anodic current densities of these surfaces were lower than those observed in the uncoated surfaces. The cathodic current densities, however, were higher for aluminum surfaces coated with PPy than for the uncoated surfaces. Breslin et al. also observed a higher rate of reduction reaction for aluminum electrode coated with a copolymer constituted of polypyrrole and polianiline electrodeposited in tosilyc acid medium than for uncoated electrode ${ }^{27}$.

In the aerated solution, the main cathodic reactions were the reduction of oxygen and PPy, since the initial doped polymer structure could be cathodically reduced. The possible chemical reactions that occur on aluminum surfaces coated by PPy films during the polarization experiments are represented below. ${ }^{28,29}$

Anodic reactions

$$
A l \rightarrow A l^{+3}+3 e^{-}
$$

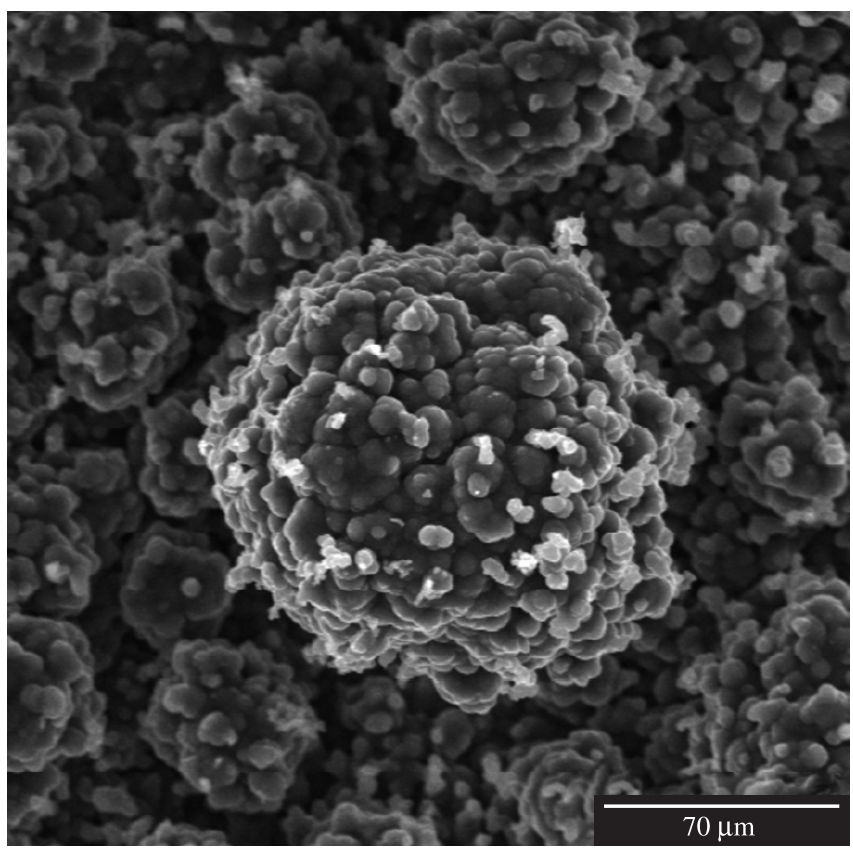

(b)

Figure 5. SEM of the aluminum surfaces coated with PPy films galvanostatically deposited at a) 5.0 and b) $10.0 \mathrm{~mA}^{\mathrm{c}} \mathrm{cm}^{-2}$. 


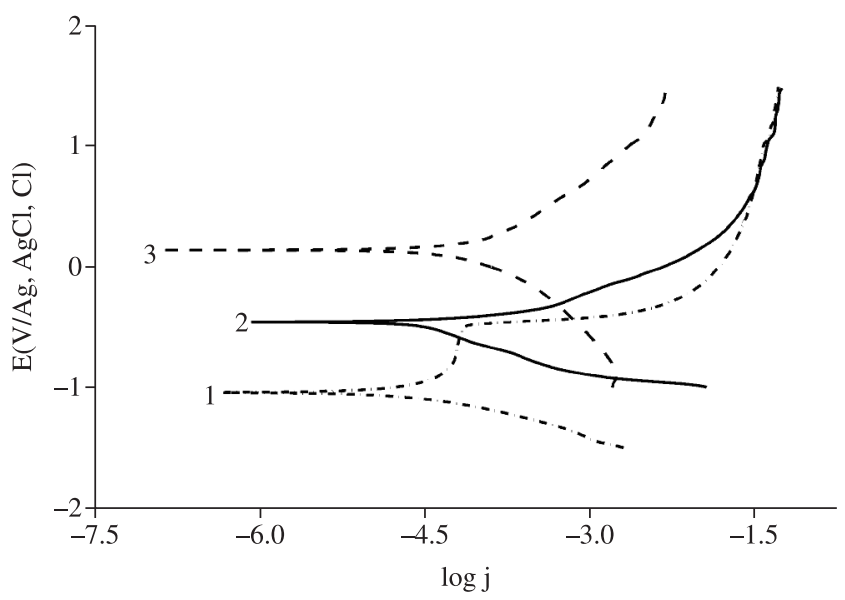

Figure 6. Polarization curves at $5 \mathrm{mV}^{-1}{ }^{-1}$ in aqueous solution $0.1 \mathrm{~mol} . \mathrm{L}^{-1}$ $\mathrm{NaCl}$ for polished aluminum surface: 1) uncoated; and coated with PPy films galvanostatically deposited at: 2) 10.0 and 3) $5.0 \mathrm{~mA} \cdot \mathrm{cm}^{-2}$.

Table 1. Corrosion parameters obtained from the polarization curves.

\begin{tabular}{ccc}
\hline Aluminum surface & ${ }^{\mathrm{a}} \mathrm{E}_{\text {corr }}(\mathrm{V})$ & ${ }^{\mathrm{b}} \mathrm{j}_{\text {corr }}\left(10^{-5} \mathrm{~mA} \mathrm{~cm}^{-2}\right)$ \\
\hline uncoated (1) & -1.03 & 3.8 \\
$\begin{array}{c}\text { coated by PPy films deposited } \\
\text { at } 10.0 \mathrm{~mA} \cdot \mathrm{cm}^{-2}(2)\end{array}$ & -0.47 & 6.7 \\
$\begin{array}{c}\text { coated by PPy films deposited } \\
\text { at 5.0 mA.cm }\end{array}$ & +0.12 & 7.7 \\
\hline
\end{tabular}

${ }^{\mathrm{a}}$ corrosion potential, ${ }^{\mathrm{b}}$ corrosion current density.

Cathodic reactions

$$
\begin{aligned}
& 2 \mathrm{H}_{2} \mathrm{O}+\mathrm{O}_{2}+4 e^{-} \rightarrow 4 \mathrm{OH}^{-} \\
& P P y_{\text {doped }}+n e^{-} \rightarrow P P y_{\text {undoped }}
\end{aligned}
$$

Surfaces coated by films deposited at $5.0 \mathrm{~mA} \cdot \mathrm{cm}^{-2}$ presented higher cathodic current densities. A higher overoxidation degree of the PPy films formed at $10.0 \mathrm{~mA} \cdot \mathrm{cm}^{-2}$ would explain the lower cathodic current densities observed for that surface (curve 2 in Figure 6), since overoxidized films are less susceptible to reduction reaction during polarization experiments.

The electrochemical parameter values obtained from the polarization curves shown in Figure 6 are presented in Table 1.

The results presented in Table 1 indicate that the corrosion current densities of the aluminum surfaces coated with PPy films were higher than those for uncoated surfaces. The occurrence of redox reactions in the polymeric matrix can also contribute to increasing the corrosion current density.

However, considering the anodic current densities as criteria for determining the corrosion protection afforded by the PPy films, the PPy coated surfaces were less susceptible to corrosion processes than uncoated aluminum. Additionally, the PPy film deposited at $5.0 \mathrm{~mA} . \mathrm{cm}^{-2}$ had better corrosion protection performance than films deposited at higher current densities. This result is ascribed to the greater homogeneity of this film (SEM micrographs).

The presence of larger voids in the cauliflower structure of the film deposited at higher current density allowed the penetration of chloride ions (aggressive species), which favored the corrosion process.

After the polarization experiment there were pits on the uncoated aluminum surface. The pitting potential was $-0.48 \mathrm{~V}$ vs. $\mathrm{Ag} / \mathrm{AgCl}$ in the curve 1 (Figure 6).
Moreover, the aluminum surfaces coated by PPy films deposited at $5.0 \mathrm{~mA} . \mathrm{cm}^{-2}$ presented smaller amount of pits after polarization experiments in chloride medium than those coated by PPy deposited at $10.0 \mathrm{~mA} \cdot \mathrm{cm}^{-2}$. The greater porosity of overoxidized PPy films allowed the penetration of aggressive species, thereby promoting pits formation on aluminum surfaces.

\section{Conclusion}

After electrodepositing polypyrrole film from aqueous solution containing p-toluene sulfonic acid onto aluminum surface, the following conclusions can be described.

The morphology of the PPy films displayed a cauliflower-like structure comprise of micro-spherical grains, which is related to dopant intercalation in the polymeric chain. Furthermore, the FTIR spectra suggest that the $\mathrm{p}$-toluene sulfonic acid was incorporated into the polymer as a dopant.

The films deposited at higher current density were more susceptible to the formation of pores and defects along the polymeric chain.

The corrosion potential of aluminum surfaces coated with polymeric films shifted to less negative values and the anodic current densities of these surfaces were lower than those observed for uncoated aluminum surfaces.

The corrosion current densities of the aluminum surfaces coated with PPy films were slightly higher than for uncoated surfaces. This can be attributed to the polymer dedoping reactions that may contribute to increasing the cathodic current densities, which explains the higher corrosion current values for PPy coated surfaces. Therefore, polymer films deposited at lower current density presented better corrosion performance.

\section{Acknowledgements}

This work was supported by the Fundação de Amparo à Pesquisa do Estado de São Paulo (FAPESP).

\section{References}

1. Jordão $\mathrm{CP}$, Silva AC, Pereira JL and Brune $W$. Contaminação por crômio de águas de rios proveniente de curtumes em Minas Gerais. Química Nova. 1999; 22(1): 47-52.

2. Ferreira ADQ. O Impacto do crômio nos sistemas biológicos. Química Nova. 2002; 25(4): 572-578.

3. Sinko J. Challenges of chromate inhibitor pigments replacement in organic coatings. Progress in Organic Coatings. 2001; 42(3-4): 267-282.

4. Twite RL and Bierwagen GP. Review of alternatives to chromate for corrosion protection of aluminum aerospace alloys. Progress in Organic Coatings. 1998; 33(2): 91-100.

5. Huerta-Vilca D, Moraes SR and Motheo AJ. Anodic treatment of aluminum in nitric acid containing aniline, previous to deposition of polyaniline and its role on corrosion. Synthetic Metals. 2004; 140(1): 23-27.

6. Tallman DE, Sokins G, Dominis A and Wallace GG. Electroactive conducting polymers for corrosion control. Journal of Solid State Electrochemistry. 2002; 6: 73-84.

7. Maksymiuk K. Chemical Reactivity of Polypyrrole and Its Relevance to Polypyrrole Based Electrochemical Sensors. Electroanalysis. 2006; 18(16): 1537-1551.

8. Wang LX, Li XG and Yang YL. Preparation, properties and applications of polypyrroles. Reactive and Functional Polymers. 2001; 47(2): 125-129.

9. Wencheng $\mathrm{S}$ and Iroh JO. Effects of electrochemical process parameters on the synthesis and properties of polypyrrole coatings on steel. Synthetic Metals. 1998; 95(3): 159-167. 
10. Naoi K, Takeda M, Kanno H, Sakakura M and Shimada A. Simultaneous electrochemical formation of $\mathrm{Al}_{2} \mathrm{O}_{3}$ /polypyrrole layers (I): effect of electrolyte anion in formation process. Electrochimica Acta. 2000; 45(20): 3413-3421.

11. Skotheim TA and Reynolds JR. Handbook of conducting polymers. $3^{\text {rd }}$ ed. Boca Raton: LLC CRC Press; 2007.

12. Akundy GS and Iroh JO. Polypyrrole coatings on aluminum - synthesis and characterization. Polymer. 2001; 42(24): 9665-9669.

13. Lehr IL and Saidman SB. Electrodeposition of polypyrrole on aluminium in the presence of sodium bis(2-ethylhexyl) sulfosuccinate. Materials Chemistry and Physics. 2006; 100(2-3): 262-267.

14. Tallman DE, Dewald MP, Vang CK, Wallace GG and Bierwagen GP. Electrodeposition of conducting polymers on active metals by electron transfer mediation. Current Applied Physics. 2004; 4(2-4): 137-140.

15. Liu AS and Oliveira MAS. Electrodeposition of polypyrrole films on aluminum from tartrate aqueous solution. Journal of Brazilian Chemical Society. 2007; 18(1): 143-152.

16. Liu AS and Oliveira MAS. Corrosion control of aluminum surfaces by polypyrrole films: influence of electrolyte. Materials Research. 2007; 10(2): 205-209.

17. Saidman SB and Bessone JB. Electrochemical preparation and characterisation of polypyrrole on aluminium in aqueous solution. Journal of Electroanalytical Chemistry. 2002; 521(1-2): 87-94.

18. Arenas MA, Bajos LG, Damborenea JJ and Ocón P. Synthesis and electrochemical evaluation of polypyrrole coatings electrodeposited onto AA-2024 alloy. Progress in Organic Coatings. 2008; 62(1): 79-86.

19. Paloumpa I, Yfantis A, Hoffmann P, Burkov Y, Yfantis D and Schmeiber D. Mechanisms to inhibit corrosion of $\mathrm{Al}$ alloys by polymeric conversion coatings. Surface and Coatings Technology. 2004; 180: 308-312.

20. Sui J, Travas-Sejdic J, Chu SY, Li KC and Kilmartin PA. The actuation behavior and stability of p-toluene sulfonate doped polypyrrole films formed at different deposition current densities. Journal of Applied Polymer Science. 111(2): 876-882.

21. Wang PC and MacDiarmid AG. Dependency of properties of in situ deposited polypyrrole films on dopant anion and substrate surface. Synthetic Metals. 2001; 119(1-3): 367-368.

22. Gaur B and Srinivasan HS. Corrosion of metals and alloys in methane sulphonic acid. British Corrosion Journal. 1999; 34(1): 63-66.

23. Mazeikien R and Malinauskas A. Kinetics of the electrochemical degradation of polypyrrole. Polymer Degradation and Stability. 2002; 75(2): 255-258.

24. Wencheng $\mathrm{S}$ and Iroh JO. Effects of electrochemical process parameters on the synthesis and properties of polypyrrole coatings on steel. Synthetic Metals. 1998; 95(3): 159-167.

25. Bazzaoui M, Martins JI, Costa SC, Bazzaoui EA, Reis TC and Martins L. Sweet aqueous solution for electrochemical synthesis of polypyrrole: Part 1-A. On non-ferrous metals. Electrochimica Acta. 2006; 51(12): 2417-2426.

26. Bazzaoui M, Martins L, Bazzaoui EA and Martins JI. New singlestep electrosynthesis process of homogeneous and strongly adherent polypyrrole films on iron electrodes in aqueous medium. Electrochimica Acta. 47(18): 2953-2962.

27. Breslin CB, Fenelon AM and Conroy KG. Surface engineering: corrosion protection using conducting polymers._Materials \& Design. 2005; 26(3): 233-237.

28. Martins NC, Silva TM, Montermor MF, Fernandes JCS and Ferreira MGS. Electrodeposition and characterization of polypyrrole films on aluminium alloy 6061-T6. Electrochimica Acta. 2008; 53(14): 4754-4763.

29. Ocon P, Cristobal AB, Herrasti P and Fatas E. Corrosion performance of conducting polymer coatings applied on mild steel. Corrosion Science. 2005; 47(3): 649-662. 
